\title{
Students' emotions during homework in mathematics: Testing a theoretical model of antecedents and achievement outcomes
}

\author{
Swantje Dettmers ${ }^{\mathrm{a}, *}$, Ulrich Trautwein ${ }^{\mathrm{b}}$, Oliver Lüdtke ${ }^{\mathrm{b}}$, Thomas Goetz ${ }^{\mathrm{c}, \mathrm{d}}$, Anne C. Frenzel ${ }^{\mathrm{e}}$, \\ Reinhard Pekrun ${ }^{\mathrm{f}}$ \\ a Max Planck Institute for Human Development, Center for Educational Research, Lentzeallee 94, 14195 Berlin, Germany \\ ${ }^{\mathrm{b}}$ University of Tübingen, Center for Educational Science and Psychology, Europastraße 6, 72072 Tübingen, Germany \\ ${ }^{\mathrm{c}}$ University of Konstanz, Empirical Educational Research, Fach 45, 78457 Konstanz, Germany \\ ${ }^{\mathrm{d}}$ Thurgau University of Teacher Education, Switzerland \\ ${ }^{\mathrm{e}}$ Department of Psychology, University of Augsburg, Universitätsstraße 10, 86159 Augsburg, Germany \\ ${ }^{\mathrm{f}}$ University of Munich, Leopoldstraße 13, 80802 Munich, Germany
}

\section{A R T I C L E I N F O}

Article history:

Available online 2 November 2010

Keywords:

Homework

Achievement emotions

Homework emotions

Effort

Academic achievement

\begin{abstract}
A B S T R A C T
The experience of pleasant and unpleasant emotions in academic situations is known to affect students' learning. The aim of the present study was to extend previous research by examining the antecedents and consequences of student emotions in the homework context. Multilevel analyses of a longitudinal dataset containing 3483 grade 9 and grade 10 students in 155 classes showed that the perceived quality of the homework tasks assigned by the teacher affected students' experience of unpleasant homework related emotions. Moreover, the experience of unpleasant emotions during homework sessions was negatively related to homework effort and negatively predicted later achievement in mathematics.
\end{abstract}

\section{Unpleasant homework-related emotions in mathematics: testing a theoretical model of antecedents and achievement outcomes}

The advantages and disadvantages of homework remain a hotly debated issue in educational psychology. There is growing evi dence that homework can be an effective supplement to in school learning (e.g., Trautwein, 2007). At the same time, it may overbur den students, causing unpleasant emotions in both students and their parents, with negative implications for family life (Corno \& Xu, 2004; Leone \& Richards, 1989). As students' emotions are not only "side effects of learning," but "an integral part of learning in close interaction with conative and cognitive processes" (Op't Eynde \& Turner, 2006, p. 362), homework related emotions can also be expected to have implications for students' academic learn ing. Yet despite a growing volume of research showing that achievement emotions significantly influence students' learning, and despite the obvious relevance of emotions to homework prac tice, there have been few attempts to systematically analyze the antecedents and consequences of students' emotions in the home work context. This study strives to fill this gap in homework research.

\footnotetext{
* Corresponding author. Fax: +49 3082406490.

E-mail address: dettmers@mpib-berlin.mpg.de (S. Dettmers).
}

\section{Achievement emotions in the homework context}

Several studies have shown that homework is often an emotion ally charged activity (e.g., Pekrun, Goetz, Titz, \& Perry, 2002; Warton, 2001). Although some students enjoy it, most report unpleasant emotions during homework sessions (Chen \& Stevenson, 1989). According to Warton (2001), the costs of homework include decreas ing motivation and increasing anxiety or boredom. Some students become so frustrated by their homework that they stop working on their assignments altogether (Corno \& Xu, 2004). In the experi ence sampling studies by Leone and Richards (1989) and Verma, Sharma, and Larson (2002), students reported more unpleasant emotions during homework than during other activities, including classwork.

How do these emotions influence students' homework behavior and achievement? Leone and Richards (1989, p. 532) pointed out that a student in a negative mood is likely to have a very different learning experience than a student in a positive mood. Similarly, Trautwein, Niggli, Schnyder, and Lüdtke (2009) argued that home work is likely to be most effective if students do not typically expe rience unpleasant emotions such as anger while doing their assignments. Trautwein, Schnyder, Niggli, Neumann, and Lüdtke (2009) found a reciprocal relationship between achievement and homework related emotions, with low achievement predicting higher levels of unpleasant homework related emotions, and high er levels of unpleasant homework related emotions predicting low 
achievement. In sum, the few studies available to date indicate that homework elicits various emotions that may impact student learn ing and achievement. However, little is known about the anteced ents and consequences of homework related emotions, and a general theoretical model for these emotions is lacking.

\section{Theoretical framework}

There are two main possibilities for integrating emotions into a homework model. First, existing models of emotions in achieve ment contexts can be adapted to the homework situation. Second, existing homework models that do not specifically include emo tions can be extended. In the present research, we integrated ele ments of the control value theory of achievement emotions (Pekrun, 2006; Pekrun, Frenzel, Goetz, \& Perry, 2007) into a home work model (Trautwein, Lüdtke, Schnyder, \& Niggli, 2006).

The control value theory of achievement emotions provides a theoretical framework for analyzing emotions in achievement related contexts. The theory combines elements from expec tancy value approaches to the study of emotions (Turner \& Schallert, 2001) with attributional theories of achievement motiva tion and emotions (Weiner, 1985). It proposes the learning envi ronment to influence two components of cognitive appraisal that are central to the development of achievement emotions. The first component, subjective control, covers control related cognitions such as self efficacy expectancies, achievement related expectan cies, and causal attributions of outcomes. The second component, subjective value, reflects the perceived valence of actions and outcomes. Emotions are a product of the two components. For instance, if the valence of homework is positive and perceived con trol is high, students are likely to enjoy doing their homework. The theory further predicts subjective control and subjective value to mediate the relationship between characteristics of the learning environment (e.g., quality of instruction) and emotional experi ence. Finally, it postulates achievement emotions to affect learning and achievement (for a more detailed description of the theory, see Pekrun, 2006; Pekrun et al., 2007). Several studies have demon strated the relevance of achievement emotions for students' moti vation, learning, and achievement. For instance, enjoyment of mathematics has been found to be positively correlated with mathematics grades (Goetz, Frenzel, Pekrun, Hall, \& Lüdtke, 2007). Summarizing several studies, Pekrun et al. (2002) found pleasant emotions such as enjoyment to predict high achievement and unpleasant emotions such as test anxiety and boredom to predict low achievement.

Trautwein et al. (2006) have proposed a domain specific, multi level homework model for the analysis of homework effects in the school context. The model predicts that the effort students put into their homework is positively related to achievement gains. It further includes elements of expectancy value theory (Eccles \& Wigfield, 2002) and proposes that homework effort is influenced by students' homework expectancy beliefs in terms of their confi dence in being able to complete a given homework task success fully ("Can I succeed on this task or activity?"; Wigfield \& Wagner, 2005, p. 224) and by homework value beliefs in terms of their beliefs that the tasks assigned are important for succeeding in a given domain, their expectancy of the activity's long term ben efits, the costs associated with doing homework, and its intrinsic value ("Why do I want to do this activity?"; Wigfield \& Wagner, 2005, p. 224). Moreover, the model predicts that homework char acteristics (e.g., homework quality in terms of the perceived qual ity of the tasks selected and the assignment of challenging but not overly difficult tasks) and student characteristics (e.g., cognitive abilities, gender) affect homework expectancy and value beliefs and homework effort. Empirical findings support the central predictions of the model (e.g., Dettmers, Trautwein, Lüdtke, Kunter,
\& Baumert, 2010; Trautwein, 2007; Trautwein \& Lüdtke, 2007; Trautwein, Lüdtke, Kastens, \& Köller, 2006; Trautwein, Lüdtke, Roberts, Schnyder, \& Niggli, 2009).

\subsection{Learning environments, achievement emotions, homework effort, and achievement}

Both control value theory and current models of homework assignment and completion include characteristics of the learning environment. The control value theory of achievement emotions postulates that characteristics of the learning environment (e.g., instructional quality and task characteristics, autonomy support, goal structures, and achievement feedback received) are crucial for the development of achievement emotions. Moreover, it pre dicts that control and value beliefs mediate the effects of these instructional characteristics on achievement emotions (Pekrun, 2006). High quality instruction that stimulates and supports stu dents' learning (e.g., through suitable learning material) may en hance the intrinsic value of achievement activities and thus contribute to the development of pleasant activity related emo tions such as enjoyment. Challenging, but solvable, tasks are thought to elicit positive emotions, whereas overly difficult/overly easy tasks may result in very low/very high control beliefs and thus lead to boredom (Else Quest, Hyde, \& Hejmadi, 2008; Pekrun, Goetz, Daniels, Stupnisky, \& Perry, 2010). Frenzel, Pekrun, and Goetz (2007) analyzed the effects of the perceived learning envi ronment (e.g., instructional quality, including aspects of clarity and structure) on emotional experience. They found that quality of instruction positively predicted enjoyment and negatively pre dicted anxiety, anger, and boredom at the student level and nega tively predicted anger at the class level.

Similarly, recent homework research has shown that aspects of the learning environment affect students' homework related emo tions (Trautwein, Niggli, et al., 2009) as well as the effort they put into their homework and, ultimately, their achievement (e.g., Dettmers et al., 2010; Trautwein \& Lüdtke, 2007; Trautwein \& Lüdtke, 2009). For instance, Trautwein, Niggli, et al. (2009) found a controlling homework style on the part of the teacher to be asso ciated with less homework effort and more unpleasant homework related emotions on the part of students in French as a second lan guage classes. In contrast, students whose teachers considered homework to be particularly helpful when done independently, and who supported students' homework autonomy by encourag ing them to complete homework assignments on their own, re ported lower levels of unpleasant homework related emotions. Likewise, quality of mathematics homework has been found to positively predict homework effort and mathematics achievement (Dettmers et al., 2010).

\subsection{A theoretical model of homework related emotions}

The present investigation in the domain of mathematics at tempts to combine the approaches of homework research and re search on achievement emotions by analyzing the effects of homework quality and expectancy value components on home work related emotions, homework effort, and achievement and examining the mediating role of homework related emotions. Spe cifically, we seek to integrate basic propositions of Pekrun's (2006) and Pekrun et al. (2007) control value theory of achievement emo tions into the homework model proposed by Trautwein, Lüdtke, Schnyder, et al. (2006). Fig. 1 presents the model analyzed in the present study. In accordance with the predictions of both theories and the results of previous studies, homework quality is proposed to predict homework expectancy and value beliefs, homework re lated emotions, homework behavior, and achievement. Two indi cators of homework quality in mathematics were analyzed in the 


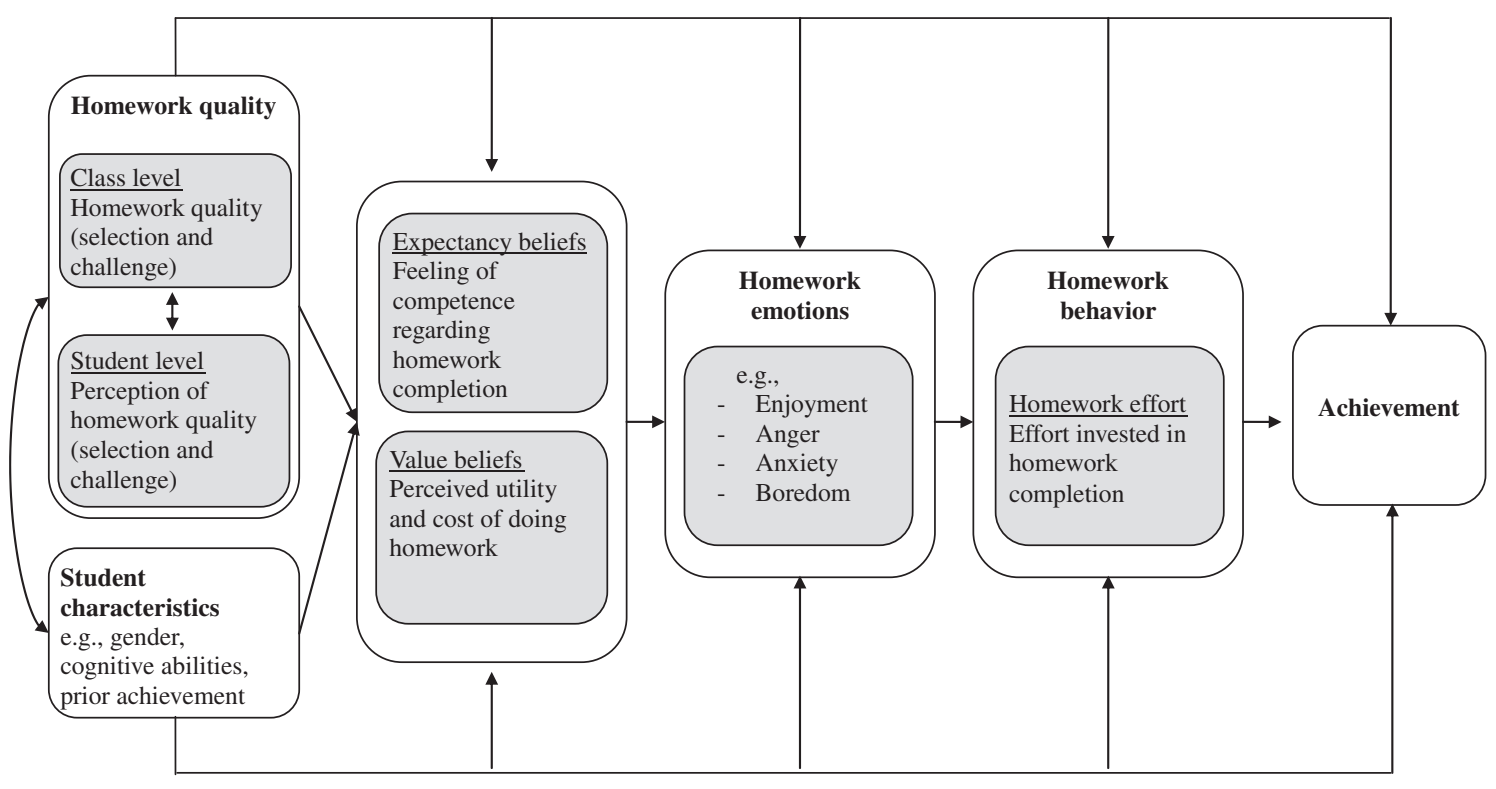

Fig. 1. Adapted version of the homework model proposed by Trautwein, Lüdtke, Schnyder, et al. (2006).

present study (see Dettmers et al., 2010). The first indicator, home work selection, can be defined as the careful selection and prepara tion of appropriate and interesting tasks that reinforce classroom learning and that are well integrated into lessons. Tasks perceived to be well selected have the potential to enhance students' under standing. High quality homework selection has been found to be positively related to homework expectancy and value beliefs. The second indicator, homework challenge, measures students' percep tions of the cognitive challenge inherent in homework tasks. Are the tasks easy to solve or do they require mental effort? Dettmers et al. (2010) described suitable tasks as tasks that cognitively chal lenge, but do not overtax students. Homework tasks that are overly challenging, or that do not present any challenge at all, may evoke unpleasant emotions such as anger, anxiety, or boredom.

In research drawing on student perceptions of instructional qual ity, it is important to take the multilevel nature of the data into ac count. As shown in Fig. 1, we differentiate between student level and class level effects (see Lüdtke, Robitzsch, Trautwein, \& Kunter, 2009) and believe both levels to be relevant in the homework con text. Student perceptions of homework quality that are aggregated to the class level yield a reliable indicator of specific features of classroom instructional quality that is relatively free of idiosyncratic student ratings (see Dettmers et al., 2010; Lüdtke et al., 2008). In somewhat simplified terms, class level effects focus on the role of teachers and their teaching, whereas student level analyses focus on differences among individual students. When two students in the same class have differing perceptions of the quality of home work in their class, this information says more about these two stu dents than about the overall quality of homework in the class. For instance, it has been shown that students who perceive their math ematics homework to be comparatively challenging report lower homework expectancy beliefs than do their classmates, but the overall perceived level of challenge in a class may be positively re lated to achievement relevant outcomes (Dettmers et al., 2010).

As argued by Trautwein, Lüdtke, Schnyder, et al. (2006) and de picted in Fig. 1, it is also important to take student characteristics such as cognitive abilities, sex, and family background into ac count. These factors have been shown to be associated with achievement related motivation and outcomes (e.g., Eccles \& Wigfield, 2002). In the present study, we use these characteristics as control variables. Our model predicts that the effects of homework quality on achievement emotions are at least partly mediated by students' expectancy and value beliefs. In turn, the experience of homework related emotions is expected to predict homework effort and achievement. Indeed, studies have shown that unpleasant emotions in the in school context lead to lower engagement and predict lower achievement (Linnenbrink, 2007; Pekrun et al., 2002), whereas pleasant emotions predict higher achievement (Pekrun et al., 2002). The same may hold for home work related emotions. Finally, the model predicts that the effects of homework quality and homework expectancy and value beliefs on homework effort and achievement are mediated by the experi ence of homework related emotions.

\section{Aims and hypotheses of the present study}

This study aims to elucidate the interrelations among students' emotional and behavioral processes in the homework context. Although there are many similarities in the antecedents and conse quences of emotions and academic effort during homework versus classwork, we consider it important to carefully distinguish between the two settings. Indeed, Trautwein et al. (2006) analyzed similarities and differences in the prediction of students' home work and classwork behaviors. Although they found an overlap be tween the two settings, confirmatory factor analyses indicated that the two domains should be considered separately, and student conscientiousness was found to have a stronger impact on home work investment and concentration than on classwork investment and concentration, further emphasizing the need to analyze school related variables in their specific setting.

The present study draws on a longitudinal dataset to describe the antecedents and consequences of homework related emotions in the domain of mathematics. We focus specifically on the domain of mathematics, examining how homework quality is related to homework emotions and subsequent engagement and achieve ment within mathematics. While similar relations might be ex pected in other domains, prior research suggests that expectancy and value beliefs, homework effort, and achievement emotions are domain specific (Goetz, Frenzel, \& Pekrun, 2006; Goetz, et al., 2007; Trautwein, Lüdtke, Schnyder, et al., 2006), thus highlighting the importance of examining these relations in domain specific 
ways. Furthermore, mathematics is a core school subject that is known to be emotionally charged for many students, and in which homework plays an important role (see Eccles \& Wigfield, 2002; Trautwein \& Lüdtke, 2007). Our study had two main purposes: (1) to examine how homework quality beliefs predict homework related emotions and (2) to examine how these emotions relate to homework behavior and achievement. We also examined poten tial mediating mechanisms. Our research hypotheses were as follows.

Hypothesis 1a. Perceived quality of homework selection is nega tively associated with unpleasant homework emotions at both the class and the student levels.

Hypothesis 1b. In general, perceived homework challenge can be expected to show a curvilinear association with unpleasant home work emotions, with very high and very low levels of perceived challenge being associated with unpleasant emotions. For the par ticular grade levels covered in the present study and the domain of mathematics, however, we expected most students to perceive homework assignments as being of medium to high difficulty. We therefore hypothesized that there would be a positive relation between perceived challenge and unpleasant emotions at the stu dent levels, but also tested for curvilinear effects (see also Pekrun et al., 2010). We did not make a prediction regarding the relation between challenge and emotions at the class level. On the one hand, the overall level of challenge in a class as an indicator of cognitively challenging instruction (see Dettmers et al., 2010) may be positively related to homework emotions. On the other hand, overly challenging tasks may be negatively associated with students' homework emotions.

Hypothesis 1c. We expected that the statistically significant asso ciations emerging between perceived quality of homework selec tion/homework challenge and homework related emotions would be (partly) mediated by homework expectancy and value beliefs.

Hypothesis 2a. Perceived quality of homework selection is posi tively associated with self reported homework effort at both the class and the student levels.

Hypothesis 2b. Perceived cognitive challenge is negatively associ ated with self reported homework effort at the student level. Again, we did not make a prediction regarding the relation between challenge and emotions at the class level.

Hypothesis 2c. Homework emotions (partly) mediate the associa tion between homework selection, homework challenge, and homework effort at both the class and the student levels.

Hypothesis 3a. The perceived quality of homework selection is positively related to student achievement at both the class and the student levels, even when prior knowledge and potential third variables are controlled.

Hypothesis 3b. Perceived cognitive challenge is negatively associ ated with mathematics achievement at the student level, even when prior knowledge and potential third variables are controlled. At the class level, perceived cognitive challenge may be an indica tor of a cognitively activating instructional style. We therefore did not expect any negative effects at the class level.
Hypothesis 3c. Homework emotions (partly) mediate the associa tion between quality of homework selection, perceived cognitive challenge, and mathematics achievement at both the class and the student levels.

\section{Method}

\subsection{Data source, design, and sample}

Our study is based on the German extension to the 2003 cycle of the Programme for Student Assessment (PISA), the PISA I Plus study (see Prenzel, Carstensen, Schöps, \& Maurischat, 2006). The goal of the extension was to measure effects of variables at the stu dent, parent, teacher, and school levels on student learning gains. A multistage sampling procedure was implemented, with whole mathematics classes being selected from the schools that were drawn to participate in the international PISA 2003 study. The stu dents were assessed twice: once in grade 9 (2003) and again in grade 10 (2004). Both assessments took place toward the end of the school year. The full student sample consisted of 4567 students from 194 classes. However, we restricted the present analyses to students who participated at both measurement points and to clas ses that did not change mathematics teachers over the period of observation. It was thus possible to analyze longitudinal effects of class level variables determined by the teacher. Moreover, in the German school system, students typically are assigned to one of four secondary tracks at the end of grade 4 or grade 6 (depend ing on the state). Because students graduate from the lowest track, the Hauptschule, after grade 9, no Hauptschule students were in cluded in the present study. The other three school types are Gym nasium (academic track, 1332 students), Realschule (intermediate track, 1576 students), and Gesamtschule (comprehensive, 210 stu dents). Some states have a Mittelschule (365 students) track com bining the Realschule and Hauptschule tracks. Our final dataset consisted of 3483 students (56.8\% female) from 155 classes. The average class size was 22.47 students. On average, the students were 15.1 years $(S D=0.57)$ old at the first assessment.

\subsection{Variables and measures}

Within the two wave design of the study, time $1(t 1)$ variables included mathematics and reading literacy, homework related emotions, homework behavior, homework expectancy and value beliefs, homework quality, and several control variables. Time 2 $(t 2)$ variables included mathematics achievement and home work related emotions.

\subsubsection{Homework quality ( $t 1$ )}

Two scales were used to assess the perceived quality of mathe matics homework assignments. Perceived quality of homework task selection was measured by five items assessing whether students perceived their homework assignments to be interesting and well prepared (e.g., "Our mathematics teacher almost always chooses homework assignments really well"; $\alpha=.83$ ). Perceived homework challenge was measured by four items assessing the perceived level of cognitive challenge of homework tasks (e.g., "Our homework mathematics assignments are often quite difficult and really make you think"; $\alpha=.74$ ). A 4 point Likert scale (from 1 = totally disagree to $4=$ totally agree) was used for both scales (Dettmers et al., 2010).

\subsubsection{Homework expectancy and value beliefs ( $t 1)$}

Homework expectancy beliefs were measured with three items (e.g., "If I make an effort, I can do all my mathematics homework"; $\alpha=.66$ ) on a 4 point Likert scale (from $1=$ totally disagree to $4=$ to tally agree). Students scoring high on homework expectancy beliefs 
are optimistic about their capability to succeed on the tasks as signed. Homework value beliefs pertained to the perceived utility and costs of mathematics homework. They were measured with two items (e.g., "Our mathematics homework takes a lot of time and is of little use to me" [reverse scored]). A 4 point Likert scale (from $1=$ totally disagree to $4=$ totally agree) was used $(\alpha=.72)$.

\subsubsection{Homework emotions ( $t 1$ and $t 2$ )}

Single item measures derived from the Achievement Emotions Questionnaire (see Pekrun et al., 2002) were used to measure the experience of enjoyment ("Doing mathematics homework puts me in a good mood"), anger ("Doing mathematics homework makes me so angry I just want to throw it out the window"), anx iety ("When I'm doing my mathematics homework, I worry whether I'm going to manage it all"), and boredom ("When doing mathematics homework assignments, I soon get bored and tired") during mathematics homework on a 4 point Likert scale ( $1=$ totally disagree to 4 = totally agree). Because Goetz et al. (2007) and Goetz, Cronjaeger, Frenzel, Lüdtke, and Hall (2010) found evidence for strong within domain relations of achievement emotions, espe cially in the domain of mathematics, we used a composite measure of emotions to test our central hypotheses. Specifically, all items were combined to form an unpleasant homework emotions scale (enjoyment reverse coded; $\alpha=.77$ at $t 1$ and .76 at $t 2$ ). Factor anal yses with SPSS 15.0 supported a one factor solution, with factor loadings ranging between .65 and .83 .

\subsubsection{Homework behavior (t1)}

The variable homework effort assessed whether students did their best to complete their mathematics homework assignments carefully (see Trautwein \& Lüdtke, 2007). Homework effort was measured by five items (e.g., "I do my best in my mathematics homework"; "I always try to complete my mathematics home work") on a 4 point Likert scale ( $1=$ totally disagree to $4=$ totally agree; $\alpha=.69$ ).

\subsubsection{Mathematics achievement ( $t 1$ and $t 2$ )}

At $t 1$, mathematics literacy was assessed with the standardized mathematics achievement test developed for PISA 2003. Scores for individual students were generated using item response theory techniques; the reliability (correlation between independent plau sible value draws, see Adams \& Wu, 2002) was $r=.77$. At $t 2$, math ematics achievement was assessed by a test developed to cover the standard content stipulated in the federal states' curricula for grade 10 students (Baumert et al., 2010). Item response techniques were again used to generate individual test scores (for further information, see Prenzel et al., 2006); the reliability was $r=.79$.

\subsubsection{Control variables ( $t 1)$}

We accounted for potential third variables by including seven $t 1$ control measures in all multilevel models. At the student level, we controlled for variables specified in the individual background model used in Baumert et al. (2010). We first controlled for effects of cognitive abilities using students' scores on the Figural Analogies subscale of the Cognitive Ability Test $4-12+R$ (Heller \& Perleth, 2000), a German version of Thorndike and Hagen's (1993) Cogni tive Abilities Test. The Figural Analogies subscale measures highly $g$ loaded ability components and is often used as a parsimonious test of cognitive abilities. Second, reading literacy was assessed by the standardized reading achievement test developed for PISA 2003. Third, socioeconomic status (SES) was assessed using the International Socio Economic Index (ISEI; Ganzeboom, de Graaf, Treiman, \& de Leeuw, 1992). ISEI scores ranged from 10 to 90; we used the highest ISEI score in the family to control for student SES. Fourth, six dummy variables were created to control for parental educational background. The six dummy variables were
PEB 1 (no apprenticeship, with or without Hauptschule certificate; lowest educational background); PEB 2 (apprenticeship, with or without Hauptschule certificate); PEB 3 (apprenticeship and Reals chule certificate); PEB 4 (Hauptschule or Realschule certificate and technical college); PEB 5 (technical college/Gymnasium certificate, no higher education); PEB 6 (degree qualification; highest educa tional background). PEB 4 (intermediate educational background) served as the reference category. Fifth and sixth, we controlled for gender and for immigration status. Finally, at the class level, we controlled for the school track attended. We created a total of four dummy variables, one for each track (Gymnasium, Realschule, Mittelschule, and Gesamtschule). Realschule was used as the refer ence category.

\subsection{Statistical analyses}

\subsubsection{Analyzing hierarchical data}

As in most studies conducted in school settings, the students in the present study were nested in classes. We therefore used a mul tilevel technique to explore relationships among variables located at different levels of the hierarchical data structure. Multilevel modeling (MLM) is a general form of regression analysis that pro vides a powerful methodology for handling nested data. MLM al lows effects to be modeled at the individual level (e.g., students), at the group level (e.g., classes), or at both levels simultaneously, and produces correct standard errors (for a detailed description of MLM, see Raudenbush \& Bryk, 2002). We differentiated between the student level (or "within class level") and the class level (or "between class level"). The multilevel models were specified using Mplus 5.1 (Muthén \& Muthén, 1998 2007). All variables were standardized to $z$ scores to simplify the interpretation of the data.

We used the multilevel latent covariate approach (MLC; see Lüdtke et al., 2008) implemented in Mplus 5.1 to control for the unreliability of aggregated student ratings of the learning environ ment. The reliability of aggregated ratings depends on the number of students per class and on the extent to which students' ratings vary across classes (Raudenbush \& Bryk, 2002). The MLC approach corrects for unreliability when estimating group effects by taking into account that only a finite number of students provided ratings of the quality of their homework.

\subsubsection{Centering student level predictor variables}

Individual and aggregated ratings of the learning environment (e.g., quality of task selection or homework challenge) were used simultaneously as predictors in the multilevel models (Lüdtke et al., 2009). Because we were primarily interested in the differing effects of homework quality and homework challenge as features of the learning environment, both classroom features were treated as class level variables, and we decided to center student ratings at the group mean. This approach allowed us to differentiate be tween class from within class variation in perceived homework characteristics (e.g., Karabenick, 2004). The other level 1 predictor variables were constructs that were primarily defined at the indi vidual level (e.g., value and expectancy beliefs, homework related emotions). These variables were centered at the grand mean, such that interindividual differences among students were taken into account (see Enders \& Tofighi, 2007, for more information on the centering of student level variables).

\subsubsection{Missing values}

Missing data represent a potentially serious problem in many empirical studies. The analyses reported in the present study are part of a larger assessment, PISA I Plus. Due to time limitations, two different versions of the assessment questionnaire were administered (multimatrix design). All students in the sample completed the items tapping homework expectancy and value 
beliefs and homework behavior, but the items on homework selection and homework challenge were contained in different assessment booklets. Thus, approximately $50 \%$ of the data for homework selection and homework challenge is missing by design (planned missingness). Apart from these two homework quality scales, $2.63 \%$ of the data were missing on average. In the method ological literature on missing data (Peugh \& Enders, 2004), there is growing consensus that multiple imputation of missing data is superior to traditional deletion methods (e.g., pairwise and listwise deletion). Hence, we opted for the multiple imputation procedure, which produces several imputations of missing values, taking into account the uncertainty of the imputed values. Five datasets were produced, in which missing data were replaced with values estimated by the PAN algorithm implemented in the $\mathrm{R}$ software (Schafer, 2008). The PAN algorithm was developed to impute multivariate panel data or clustered data. PAN uses a multivariate extension of a two level linear regression model commonly ap plied to multilevel data (Schafer, 2001). The resulting estimates were combined using the formulas given by Rubin (1987) that are implemented in Mplus.

\section{Results}

\subsection{Descriptives and intercorrelations}

The unstandardized means, standard deviations, and intercorre lations of the main analysis variables are reported in Table 1, sep arately for the student level (below the diagonal) and the class level (above the diagonal). At $M=2.69$, the students judged the quality of homework selection to be moderate. Similarly, the mean for homework challenge was slightly above the midpoint (2.50) of the scale, at $M=2.75$. The mean for unpleasant homework emo tions $(M=2.21)$ was somewhat below the scale midpoint. Further, the students reported moderate to high levels of homework expec tancy and value beliefs and moderate levels of homework effort.

In the next step, we analyzed the intercorrelations among the variables (see Table 1). Overall, the correlations were in the ex pected direction, and a similar pattern of associations was found for $t 1$ and $t 2$ homework emotions. At the student level, higher mathematics achievement was associated with a lower level of unpleasant homework related emotions. Similarly, students who perceived their homework to be well selected reported lower lev els of unpleasant homework emotions, whereas students who felt challenged by their tasks reported higher levels of negative home work emotions. Both homework value and expectancy were nega tively related to unpleasant homework emotions. Moreover, unpleasant homework emotions were negatively associated with homework effort.

For most variables, the absolute size of the correlations was considerably higher at the class level than at the student level this pattern is well known from student achievement studies. The sign of the correlations was typically the same at both levels with one notable exception. Homework challenge was positively associated with achievement, value, expectancy, and effort, and negatively associated with unpleasant homework emotions at the between class level, but negatively associated with achievement, value, expectancy, and effort, and positively associated with unpleasant homework emotions at the within class level. In line with the results from the Dettmers et al. (2010) study, these findings again highlight the need to consider the class and student levels separately when probing for the effects of homework quality indicators.

\subsection{Predicting unpleasant homework related emotions}

Hypotheses 1a and 1b described the predicted association between the perceived quality of homework selection/homework challenge and unpleasant homework emotions. We expected that a high perceived quality of homework selection would be nega tively associated and that perceived homework challenge would be positively associated with unpleasant homework emotions at both the class (homework selection) and the student levels (home work selection/challenge). Furthermore, we examined whether there was support for a curvilinear association, with lower levels of unpleasant homework emotions at medium levels of challenge.

To test these hypotheses, we specified a multilevel regression analysis. In this analysis, $t 1$ unpleasant homework emotions were controlled by specifying this variable as a predictor variable. Fur thermore, all class level and student level control variables (see Method section) were included. The results of the analysis are re ported as model M1 in Table 2. As expected, unpleasant homework emotions at $t 1$ predicted unpleasant homework emotions at $t 2$ $(B=.50, p<.001)$. Furthermore, as hypothesized (hypothesis $1 \mathrm{a}$ ), a high perceived quality of homework selection negatively pre dicted $t 2$ unpleasant homework emotions at both the class and the student level the higher the perceived homework quality, the lower the level of unpleasant homework emotions. We also found support for the prediction (hypothesis $1 \mathrm{~b}$ ) that perceived homework challenge would be positively associated with

Table 1

Means and intercorrelations at the between-level (above the diagonal) and at the within-level (below the diagonal).

\begin{tabular}{|c|c|c|c|c|c|c|c|c|c|c|c|c|c|c|c|c|}
\hline & & 1 & 2 & 3 & 4 & 5 & 6 & 7 & 8 & 9 & 10 & 11 & 12 & 13 & $M$ & $S D$ \\
\hline 1 & Math. ach. $t 2$ & & 0.98 & 0.90 & 0.96 & 0.77 & 0.34 & 0.05 & 0.17 & 0.26 & -0.36 & -0.52 & -0.37 & -0.06 & 571.22 & 79.44 \\
\hline 2 & Math. ach. $t 1$ & 0.49 & & 0.94 & 0.96 & 0.81 & 0.37 & -0.05 & 0.17 & 0.17 & -0.38 & -0.45 & -0.29 & -0.19 & 0.23 & 0.87 \\
\hline 3 & Cognitive abilities & 0.36 & 0.39 & & 0.94 & 0.77 & 0.27 & -0.05 & 0.07 & 0.23 & -0.37 & -0.47 & -0.33 & -0.08 & 0.26 & 1.35 \\
\hline 4 & Reading ach. $t 1$ & 0.28 & 0.28 & 0.20 & & 0.83 & 0.32 & 0.03 & 0.11 & 0.28 & -0.34 & -0.59 & -0.38 & -0.01 & 0.35 & 1.12 \\
\hline 5 & SES & 0.06 & 0.09 & 0.03 & 0.08 & & 0.20 & 0.07 & 0.02 & 0.08 & -0.21 & -0.37 & -0.35 & -0.17 & 52.83 & 15.96 \\
\hline 6 & Immigration status & 0.08 & 0.10 & 0.01 & 0.09 & 0.15 & & -0.13 & 0.22 & -0.22 & -0.19 & 0.07 & 0.22 & -0.23 & 0.80 & 0.40 \\
\hline 7 & HW selection & -0.01 & -0.02 & -0.05 & 0.10 & -0.05 & -0.03 & & -0.42 & 0.73 & 0.58 & -0.66 & -0.84 & 0.70 & 2.69 & 0.68 \\
\hline 8 & HW challenge & -0.27 & -0.24 & -0.17 & -0.15 & -0.04 & -0.01 & -0.16 & & 0.30 & 0.65 & 0.37 & 0.52 & 0.30 & 2.75 & 0.70 \\
\hline 9 & HW value & -0.01 & -0.05 & -0.03 & 0.01 & -0.02 & -0.03 & 0.38 & -0.08 & & 0.36 & -0.78 & -0.88 & 0.75 & 3.04 & 0.83 \\
\hline 10 & HW expectancy & 0.20 & 0.12 & 0.10 & 0.02 & 0.06 & -0.02 & 0.27 & -0.36 & 0.18 & & -0.14 & -0.43 & 0.48 & 2.96 & 0.70 \\
\hline 11 & HW emotions $t 2$ & -0.26 & -0.16 & -0.16 & -0.11 & -0.04 & -0.03 & -0.22 & 0.32 & -0.30 & -0.32 & & 0.86 & -0.52 & 2.20 & 0.71 \\
\hline 12 & HW emotions $t 1$ & -0.20 & -0.14 & -0.15 & -0.12 & -0.02 & 0.01 & -0.33 & 0.35 & -0.48 & -0.40 & 0.58 & & -0.60 & 2.21 & 0.71 \\
\hline \multirow[t]{3}{*}{13} & HW effort & 0.16 & 0.10 & 0.07 & 0.15 & 0.01 & 0.04 & 0.22 & -0.25 & 0.26 & 0.29 & -0.36 & -0.45 & & 2.69 & 0.63 \\
\hline & $M$ & 570.58 & 0.23 & 0.26 & 0.36 & 52.77 & 0.80 & 2.69 & 2.75 & 3.04 & 2.96 & 2.21 & 2.21 & 2.69 & & \\
\hline & $S D$ & 47.90 & 0.50 & 0.71 & 0.63 & 7.53 & 0.18 & 0.34 & 0.31 & 0.28 & 0.20 & 0.22 & 0.23 & 0.18 & & \\
\hline
\end{tabular}

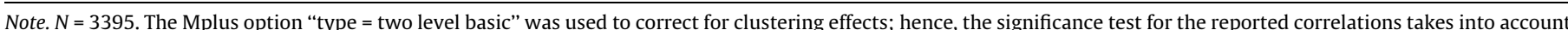

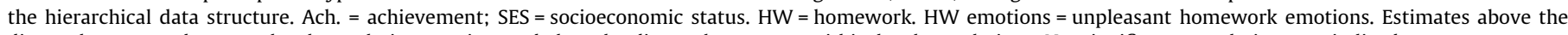
diagonal represent between-level correlations; estimates below the diagonal represent within-level correlations. Nonsignificant correlations are italized. 
Table 2

Predicting unpleasant homework emotions: results from multilevel modeling.

\begin{tabular}{lcc}
\hline & M1 & M2 \\
\hline Level 2: classes & & \\
School type (reference category: middle track) & & \\
Mittelschule (lower track) & 0.04 & 0.05 \\
Gymasium (highest track) & 0.07 & 0.06 \\
Gesamtschule (comprehensive) & 0.10 & 0.10 \\
Homework selection $t 1$ & $-0.14^{*}$ & $-0.14^{*}$ \\
Homework challenge $t 1$ & 0.01 & 0.01 \\
& & \\
Level 1: students & & \\
Mathematics achievement $t 1$ & $-0.05^{*}$ & $-0.05^{* *}$ \\
Cognitive abilities $t 1$ & $-0.05^{* *}$ & $-0.05^{* *}$ \\
Reading achievement $t 1$ & -0.03 & -0.03 \\
SES & -0.01 & -0.01 \\
Male & $0.07^{* *}$ & $0.07^{* * *}$ \\
Immigration status & $-0.08^{* *}$ & $-0.09^{*}$ \\
PEB 1 & -0.11 & -0.11 \\
PEB 2 & 0.03 & 0.02 \\
PEB 3 & 0.01 & 0.01 \\
PEB 4 & -0.04 & -0.04 \\
PEB 5 & -0.01 & 0.00 \\
Homework selection $t 1$ & $-0.06^{*}$ & -0.03 \\
Homework challenge $t 1$ & $0.13^{* * *}$ & $0.12^{* * *}$ \\
Homework value $t 1$ & & $-0.04^{*}$ \\
Homework expectancy $t 1$ & & $-0.07^{* * *}$ \\
Unpleasant homework emotions $t 1$ & $0.50^{* * *}$ & $0.46^{* * *}$ \\
$R^{2}$ level 2 & 0.78 \\
$R^{2}$ level 1 & 0.36 & 0.37 \\
\hline
\end{tabular}

Note. $N$ 3483. Unstandardized regression coefficients are reported. M1 = models without homework expectancy and value beliefs. $M 2=$ complete models. $t 1=$ first measurement point; SES = socioeconomic status; $\mathrm{PEB}=$ parental educational background. Higher PEBs indicate a higher parental educational background. Reference category: PEB 4 (Hauptschule or Realschule certificate and technical college; medium level of education).

${ }^{*} p<.05$.

*** $p<.01$.

$p<.001$.

unpleasant homework emotions at the student level. In contrast, homework challenge was not significantly associated with unpleasant homework emotions at the class level. In model M1, the amount of explained variance (calculated as the change in the variance components for the two levels as reported by Mplus) was $R^{2}=.78$ (class level) and $R^{2}=.36$ (student level). Finally, we tested if the relation between homework challenge and home work related emotions was curvilinear by introducing the qua dratic effects at both the class and student level in an additional model. There were no significant quadratic effects.

Hypothesis 1c predicted that the statistically significant associ ations found between perceived quality of homework selection/ homework challenge and homework related emotions would be (partly) mediated by homework expectancy and value beliefs. Re sults for the direct effects are reported as model M2 in Table 2. We examined the statistical significance of the indirect effects by using the procedures suggested by Krull and MacKinnon (2001) for test ing mediated effects at the student and class level. More specifi cally, the regression coefficients and standard errors of both the paths from the predictor to the mediator and from the mediator to the outcome were used to calculate a total indirect effect and the corresponding standard error. Before specifying the mediation analyses, we tested whether selection and challenge statistically significantly predicted expectancy and value beliefs, and this was indeed the case (all ps<.05). Furthermore, we only tested for mediation effects if the direct effect from the predictor to the out come was significant when the mediator variable was not in cluded. As can be seen in Table 2 (M1), this was not the case for class level homework challenge. Hence, a total of six indirect ef fects from the predictors (class /student level selection and stu dent level challenge) through the mediators (expectancy and value beliefs) to the outcome (unpleasant homework emotions) were tested. Of these six mediated effects, five were statistically significant; thus, our hypothesis was largely supported. Homework value beliefs mediated the effects from student level selection $(.28 \times-.04 ; S E=.01 ; p<.05)$, class level selection $(.22 \times .04 ; S E$ $<.01 ; p<.05)$, and student level challenge $(.09 \times-.04 ; S E=.01$; $p<.05)$ on unpleasant homework emotions. Homework expec tancy beliefs mediated the effects from student level selection $(.18 \times-.07 ; \quad S E=.01 ; p<.001)$ and student level challenge $(-.24 \times-.04 ; S E<.01 ; p<.001)$ on unpleasant homework emo tions. The effect of class level selection on unpleasant homework emotions was not statistically significantly mediated by expec tancy beliefs $(-.02 \times-.07 ; S E<.01 ; n s)$. The size of the regression coefficients for homework selection at the student level decreased from $-.06(p<.05)$ to $.03(n s)$, whereas the other coefficients were only slightly affected.

\subsection{Predicting homework effort}

In the next step, we tested hypotheses $2 \mathrm{a}$ and $2 \mathrm{~b}$ that the per ceived quality of homework selection would be positively associ ated (class and student levels) and that perceived homework challenge would be negatively associated (student level) with self reported homework effort. Furthermore, we expected that homework emotions would (partly) mediate the association between homework quality and homework effort at both the class and student levels (hypothesis 2c). We ran three separate multi level regression models to test these hypotheses. Again, the home work quality indicators and all control variables were entered in the first model. Expectancy and value beliefs were added as predic tor variables in model M2. Finally, unpleasant homework emotions were included in M3.

As shown by M1 in Table 3, and in line with our hypothesis, homework effort was positively predicted by the perceived quality of homework selection at the student level. Hence, students who perceived their homework assignments to be well selected put more effort into their homework than did other students. At the class level, as expected, we likewise found students in classes where homework was generally perceived to be well selected to put more effort into their homework than students in other classes. In contrast, again supporting our hypothesis, perceived homework challenge negatively predicted homework effort at the student le vel, indicating that students who perceived their homework assignments to be (too) challenging put less effort into their home work than did other students. No significant predictive effect was found for class level homework challenge. In model M1, the amount of explained variance was $R^{2}=.56$ (class level) and $R^{2}=.11$ (student level).

In M2, homework value and expectancy beliefs were added as additional predictors. Both variables positively predicted home work effort. The amount of explained variance increased to $R^{2}=.78$ (class level) and $R^{2}=.15$ (student level), and the absolute size of the direct effects for homework selection and challenge de creased markedly.

In M3, unpleasant homework emotions were added as an addi tional predictor variable. Unpleasant homework emotions signifi cantly predicted homework effort. Students who experienced high levels of unpleasant emotions while doing their homework put less effort in their assignments than did other students. The amount of explained variance was $R^{2}=.73$ (class level) and $R^{2}=.23$ (student level). We next tested whether unpleasant home work emotions (partly) mediated the statistically significant effects from student and class level homework selection and student le vel challenge to homework effort (see hypothesis $2 \mathrm{c}$ ). In line with our expectations, all three mediation analyses yielded support for 
Table 3

Predicting homework effort: results from multilevel modeling.

\begin{tabular}{lccc} 
& M1 & M2 & M3 \\
\hline Level 2: classes & & & \\
School type (reference category: middle track) & & \\
Mittelschule (lower track) & -0.05 & -0.03 & 0.03 \\
Gymnasium (highest track) & $-0.23^{* * *}$ & $-0.20^{* * *}$ & $-0.18^{* * *}$ \\
Gesamtschule (comprehensive) & -0.01 & -0.03 & -0.03 \\
HW selection & $0.27^{* *}$ & $0.17^{* *}$ & 0.07 \\
HW challenge & -0.10 & -0.03 & 0.03 \\
& & & \\
Level 1: students & & & \\
Mathematics achievement $t 1$ & $0.06^{* *}$ & $0.06^{* *}$ & 0.04 \\
Cognitive abilities $t 1$ & 0.00 & -0.01 & -0.04 \\
Reading achievement $t 1$ & $0.06^{* *}$ & $0.07^{* *}$ & 0.05 \\
SES & -0.02 & -0.02 & -0.02 \\
Male & $-0.21^{* * *}$ & $-0.20^{* * *}$ & $-0.21^{* * * *}$ \\
Immigration status & 0.07 & 0.09 & 0.08 \\
PEB 1 & 0.02 & 0.01 & -0.03 \\
PEB 2 & 0.10 & 0.12 & 0.13 \\
PEB 3 & -0.07 & -0.07 & -0.06 \\
PEB 4 & -0.09 & -0.09 & -0.09 \\
PEB 5 & 0.01 & -0.01 & -0.02 \\
Homework selection $t 1$ & $0.20^{* * * *}$ & $0.07^{* *}$ & 0.04 \\
Homework challenge $t 1$ & $-0.20^{* * *}$ & $-0.13^{* * *}$ & -0.05 \\
Homework value $t 1$ & & $0.19^{* * *}$ & $0.05^{*}$ \\
Homework expectancy $t 1$ & & $0.20^{* * *}$ & $0.13^{* * *}$ \\
Unpleasant homework emotions $t 1$ & & & $-0.36^{* * * *}$ \\
$R^{2}$ Level 2 & 0.56 & 0.78 & 0.73 \\
$R^{2}$ Level 1 & 0.11 & 0.15 & 0.23 \\
\hline
\end{tabular}

Note. $N$ 3483. Unstandardized regression coefficients. M1 = models without unpleasant homework emotions. M2 = complete models. SES = socioeconomic status; $\mathrm{PEB}=$ parental educational background. Higher PEBs indicate a higher parental educational background. Reference category: PEB 4 (Hauptschule or Realschule certificate and technical college; medium level of education).

${ }^{*} p<.05$.

** $p<.01$.

*** $p<.001$

(partial) mediation. Perceived homework quality was significantly associated with unpleasant homework emotions. The effects of class average homework selection $(-.24 \times-.36 ; S E=.02$; $p<.001$ ) were statistically significantly mediated by the experi ence of unpleasant homework related emotions. The same was found for homework selection $(-.28 \times-.36 ; S E=.01 ; p<.05)$ and homework challenge $(.21 \times-.36 ; S E=.01 ; p<.001)$ as student le vel variables. The absolute size of the regression coefficients for homework selection and challenge decreased further. These find ings indicate that homework related emotions mediate the rela tionship between both homework quality scales and homework effort.

\subsection{Predicting mathematics achievement}

Our third hypothesis predicted that the perceived quality of homework selection (student and class levels) and homework challenge (student level) would be associated with mathematics achievement, even when prior knowledge and potential third vari ables were controlled (hypothesis 3a and $3 \mathrm{~b}$ ). Furthermore, home work emotions were expected to (partly) mediate the association between homework quality (student and class levels) and mathe matics achievement (hypothesis $3 \mathrm{~b}$ ). To test these hypotheses, we ran a set of four multilevel regression analyses. The results are reported in Table 4 . As shown by M1, mathematics achieve ment at $t 1$ and several of the control variables predicted mathe matics achievement at $t 2$. With respect to the mathematics homework quality indicators, we found homework challenge to be negatively related to achievement at the student level, indicat ing that students who perceived their homework assignments to
Table 4

Predicting mathematics achievement: results from multilevel modeling.

\begin{tabular}{|c|c|c|c|c|}
\hline & M1 & M2 & M3 & M4 \\
\hline \multicolumn{5}{|l|}{ Level 2: classes } \\
\hline \multicolumn{5}{|c|}{ School type (reference category: middle track) } \\
\hline Mittelschule (lower track) & -0.02 & -0.03 & 0.00 & -0.01 \\
\hline Gymnasium (highest track) & $0.18^{* * * *}$ & $0.21^{* * *}$ & $0.21^{* * *}$ & $0.22^{* * *}$ \\
\hline Gesamtschule (comprehensive) & $-0.18^{*}$ & $-0.20^{* *}$ & $-0.20^{* *}$ & $-0.20^{*}$ \\
\hline HW selection & $0.20^{* *}$ & $0.18^{*}$ & 0.14 & 0.14 \\
\hline HW challenge & $0.26^{* * *}$ & $0.29^{* * * *}$ & $0.32^{* * * *}$ & $0.32^{* * * *}$ \\
\hline \multicolumn{5}{|l|}{ Level 1: students } \\
\hline Mathematics achievement $t 1$ & $0.35^{* * *}$ & $0.35^{* * *}$ & $0.35^{* * *}$ & $0.34^{* * *}$ \\
\hline Cognitive abilities $t 1$ & $0.17^{* * *}$ & $0.17^{* * *}$ & $0.16^{* * *}$ & $0.17^{* * *}$ \\
\hline Reading achievement $t 1$ & $0.13^{* * *}$ & $0.13^{* * * *}$ & $0.13^{* * *}$ & $0.13^{* * *}$ \\
\hline SES & -0.01 & -0.01 & -0.01 & -0.01 \\
\hline Male & $0.09^{* *}$ & $0.08^{* *}$ & $0.08^{* *}$ & $0.09^{* * *}$ \\
\hline Immigration status & 0.05 & 0.05 & 0.05 & 0.05 \\
\hline PEB 1 & -0.13 & -0.14 & -0.14 & -0.14 \\
\hline PEB 2 & -0.09 & -0.09 & -0.08 & -0.09 \\
\hline PEB 3 & -0.05 & -0.05 & -0.05 & -0.05 \\
\hline PEB 4 & -0.07 & -0.07 & -0.07 & -0.07 \\
\hline PEB 5 & 0.01 & 0.00 & -0.01 & 0.00 \\
\hline Homework selection $t 1$ & 0.00 & -0.02 & -0.02 & -0.03 \\
\hline Homework challenge $t 1$ & $-0.11^{* * * *}$ & $-0.08^{* * * *}$ & $-0.07^{* *}$ & $-0.06^{* * *}$ \\
\hline Homework value $t 1$ & & 0.00 & -0.02 & -0.03 \\
\hline Homework expectancy $t 1$ & & $0.08^{* * * *}$ & $0.07^{* * *}$ & $0.06^{* * *}$ \\
\hline $\begin{array}{l}\text { Unpleasant homework emotions } \\
\quad t 1\end{array}$ & & & $-0.07^{* * *}$ & $-0.06^{* *}$ \\
\hline Homework effort $t 1$ & & & & $0.04^{* * *}$ \\
\hline$R^{2}$ Level 2 & 0.93 & 0.92 & 0.92 & 0.92 \\
\hline$R^{2}$ Level 1 & 0.32 & 0.32 & 0.33 & 0.33 \\
\hline
\end{tabular}

Note. $N$ 3483. Unstandardized regression coefficients. M1 = models without unpleasant homework emotions. M2 = complete models. SES = socioeconomic status; $\mathrm{PEB}=$ parental educational background. Higher PEBs indicate a higher parental educational background. Reference category: PEB 4 (Hauptschule or Realschule certificate and technical college; medium level of education).

${ }^{*} p<.05$.

*** $p<.01$

*** $p<.001$.

be comparatively challenging showed lower achievement gains than did other students. However, at the class level, both home work quality scales positively predicted mathematics achieve ment. Hence, students in classes where homework assignments were generally perceived to be well selected and challenging showed greater achievement gains than did students in other clas ses. The amount of explained variance was $R^{2}=.93$ (class level) and $R^{2}=.32$ (student level).

Expectancy and value beliefs were added in M2, and unpleasant homework emotions were added in M3. Homework expectancy beliefs and homework emotions significantly predicted mathemat ics achievement at $t 2$. As shown by M3, mathematics achievement was negatively related to the experience of unpleasant emotions during mathematics homework. Thus, students who experienced high levels of unpleasant emotions while doing their homework showed lower achievement gains in mathematics than did other students. The size of the regression coefficients for homework selection and challenge were only slightly affected; in fact, the regression coefficient for homework challenge at the class level in creased from .26 to .29 . This increase points to a suppressor effect, indicating that homework challenge was even more positively associated with achievement when (the negative effects of home work challenge on) homework value and expectancy beliefs were controlled for. The amount of explained variance was $R^{2}=.92$ (class level) and $R^{2}=.33$ (student level).

We next examined whether unpleasant homework emotions mediated the effect of homework quality on mathematics achieve ment at $t 2$. We tested mediation effects only for those predictor 
variables that were significantly associated with $t 2$ achievement in M2. An additional analysis confirmed that the homework quality indicators were significantly associated with the mediator. The ef fects of class average homework selection $(-.24 \times-.07 \mathrm{SE}=.01$; $p<.01$ ) were statistically significantly mediated by the experience of unpleasant homework related emotions. The same was found for class average homework challenge $(.18 \times-.07 ; \quad S E<.01$; $p<.05)$ and for student level homework challenge $(.21 \times-.07$; $S E<.01 ; p<.001)$. Whereas the regression coefficient for class level homework selection decreased, there was again a small suppression effect for class level homework challenge. These findings indicate that homework related emotions mediated the association between the homework quality scales and $t 2$ achievement.

Finally, we ran an analysis in which homework effort was in cluded as an additional predictor variable (see M4). As Table 4 indi cates, homework effort was found to predict $t 2$ achievement, but the inclusion of homework effort only marginally affected the pat tern of the other results.

\section{Discussion}

The present study was designed to explore the antecedents of homework related emotions in mathematics and their conse quences for homework behavior and later achievement in the sub ject. Findings based on a longitudinal dataset showed that perceived homework quality played an important role in the prediction of homework related emotions. Consistent Goetz, Cronjaeger, et al. (2010), Goetz, Nett, et al., (submitted for publica tion)with the predictions of Pekrun's (2006); Pekrun et al., 2007) control value theory of achievement emotions, these effects were mediated by students' homework expectancy and value beliefs. In addition, the experience of unpleasant homework related emo tions was negatively associated with homework effort and nega tively predicted achievement in mathematics, even when prior achievement and several other powerful predictor variables were controlled. Although the effect sizes for homework emotions were rather small, they should be considered meaningful considering that we controlled for many other variables.

\subsection{Antecedents and consequences of homework related emotions}

Our results were congruent with the findings of previous stud ies on the antecedents and consequences of general academic achievement emotions (see Frenzel et al., 2007; Goetz, Cronjaeger, et al. (2010), Goetz, Nett, et al. (submitted for publication), Pekrun et al. (2002) and extended this prior research to the specific con text of mathematics homework. At the same time, our findings ex tended previous research on homework (e.g., Dettmers et al., 2010; Trautwein, Lüdtke, Schnyder, et al., 2006), by focusing on the ne glected role of homework related emotions. We found that stu dents who perceived their homework assignments to be well selected reported lower levels of unpleasant homework emotions than did other students. This association held at both levels of analyses. Furthermore, we found that students who perceived their homework tasks to be challenging reported higher levels of unpleasant homework emotions than did other students (stu dent level effect only). In turn, homework emotions were signifi cantly related to homework effort and achievement at $t 2$.

One of the strengths of our study was the careful separation of class level and student level effects. This separation proved to be important. Specifically, we found differential patterns of associa tions between homework challenge and other homework variables at the student versus class level. Homework challenge was statisti cally significantly associated with homework emotions and home work effort at the student level, but not at the class level. Furthermore, challenging homework assignments were positively associated with $t 2$ achievement at the class level, but negatively associated at the student level. Hence, at the class level, high chal lenge seems to be a quality indicator, whereas at the student level, it may signify that the student is overtaxed.

Overall, our results suggest that students would benefit from developing effective emotional coping strategies for homework. It seems worth analyzing the antecedents and consequences of homework related emotions in more detail, especially as previous studies have shown that unpleasant achievement emotions im pede not only cognitive abilities, performance, and working mem ory but also students' psychological and physical health (Pekrun et al., 2002). The same may hold for homework related emotions. Moreover, there may be a close relationship between negative feel ings in school and negative feelings about homework. Warton (2001) warned that setting homework may be counterproductive if negative homework related emotions are entrenched, in which case homework may inhibit desired outcomes, such as positive attitudes towards schooling or the development of learning abilities.

\subsection{Educational implications}

What are the educational implications of our findings? The con trol value theory of achievement emotions suggests that high quality instruction fosters the development of high control and va lue beliefs and thus enhances the experience of pleasant achieve ment emotions (Pekrun, 2006; Pekrun et al., 2007). The present results support this hypothesis in the homework context, empha sizing that in order to trigger pleasant rather than unpleasant homework related emotions in mathematics teachers need to set interesting homework assignments that are well integrated into lessons, that reinforce classroom learning, and that are not too challenging. Future studies can provide further insights into the development of homework related emotions and pinpoint practical implications for high quality homework by examining which characteristics of homework assignments enhance the expe rience of pleasant emotions and which elicit unpleasant emo tions. Homework research has found easy and repetitive homework tasks to be negatively related to achievement (Cooper, 1989). Moreover, research on general instructional quality has shown cognitively activating tasks to be positively linked to effort and achievement (Kunter \& Baumert, 2006). Similar patterns of re sults might be expected to emerge between these constructs and homework emotions.

How else might students' experience of pleasant homework re lated emotions be fostered? First, Pekrun (2006) suggested enhancing students' control and value beliefs by providing an autonomy supportive learning environment. Trautwein, Niggli, et al. (2009) showed that students whose teachers encouraged them to complete their homework tasks on their own reported lower levels of unpleasant homework related emotions than did other students. Giving students a say in the choice of homework assignments may also help to promote pleasant homework related emotions. Second, tasks that satisfy students' needs (e.g., authentic tasks) are believed to enhance students' value beliefs and thus to foster the experience of pleasant achievement emotions (Pekrun, 2006). Assigning homework assignments that are adapted to stu dents' needs may thus also foster the development of pleasant homework related emotions. Third, teacher feedback can play an important role. Elaborated, informative feedback may increase the experience of pleasant homework related emotions, especially if students are evaluated relative to their own previous achieve ment rather relative to the rest of the class (Goetz, Frenzel, Hall, \& Pekrun, 2008). 
Finally, teachers and parents can help students to learn how to regulate achievement emotions (Pekrun, 2006). To date, few stud ies have analyzed the self regulation of achievement emotions in the homework context. Xu (2005) administered a scale assessing students' homework emotion management strategies (e.g., "cheer ing myself up and telling myself that I can do it") and found stu dents who received family help with their homework to monitor and control their homework related emotions more often than other students did. However, this finding does not imply that it is the responsibility of students or their families to develop emo tional regulation strategies if homework is an aversive experience. Rather, is the teacher's responsibility to help students to develop the necessary self regulation strategies although not all teachers share this view (see Trautwein, Niggli, et al., 2009).

\subsection{Limitations of the present study and future research}

With its large sample size, longitudinal dataset, and subject specificity, the present study provides well founded insights into how the learning environment influences the development of homework related emotions and how these emotions in turn influ ence homework behavior and later achievement. At the same time, the present research has certain limitations. First, self reports were our sole source of information about students' homework related emotions. Although self reports provide important insights into how students perceive and interpret situations (Op't Eynde and Turner, 2006), their use presents two risks: (a) socially desirable responding and (b) students not necessarily being fully aware of their own emotions (Else Quest et al., 2008). Indeed, self reports have been found to be only loosely connected to other measures of emotions (Cacioppo, Berntson, Larsen, Poehlmann, \& Ito, 2000). According to Meyer and Turner (2006), the complexity of achieve ment emotions can be fully understood only by measuring emo tions from different viewpoints, including those of students, teachers, and external observers. Analyzing homework related emotions from multiple perspectives using physiological mea sures, behavioral measures (e.g., videotaped facial expressions), diary studies, or the experience sampling method can help to elu cidate the mechanisms surrounding emotions in homework re lated settings.

A second limitation concerns our decision to use a general homework emotions scale in the analyses, rather than reporting results for discrete emotions such as anger, joy, and boredom. The emotions included in the present study formed a reliable homework emotions scale; hence, the use of this general scale was justified. At the same time, supplementary analyses with the single item indicators of the four emotions (results are available on request from the first author) indicate that there may be some variability across the emotions in their specific relations with homework quality and achievement outcomes. Unfortunately, sin gle item indicators entail two problems: their variability is limited and they may not fully capture the intended emotion. In sum, the emotion specific relations warrant further investigation, but future studies should use multi item scales to assess discrete homework related emotions.

Third, our measure of homework value is not fully aligned with the conceptualization of value in the control value theory of achievement emotions. We assessed homework value by asking students to rate the perceived value and costs of homework, whereas the control value theory of achievement emotions postu lates that the positive and negative values of achievement activi ties and their outcomes are crucial for achievement emotions.

A fourth limitation concerns the directions of relationships found in the present study. Despite the longitudinal study design, we were not able to satisfactorily address the issue of causation. Because our study was nonexperimental, it is impossible to ex clude the possibility of third variable explanations. In other words, other predictor variables may have affected the outcome variables analyzed. Furthermore, recent studies have shown that home work related emotions and achievement are linked by reciprocal causation (Trautwein, Schnyder, et al., 2009). Experimental ap proaches are needed to gain a deeper understanding of the dynam ics of homework related emotions, homework behavior, and student achievement.

Fifth, the present results are specific to mathematics. Goetz, Frenzel, and Pekrun (2006) and Goetz et al. (2007) showed that achievement emotions are organized in a domain specific manner. As noted above, we believe homework emotions to be highly rele vant in the field of mathematics a core school subject that is known to be emotionally charged for many students, and in which homework plays an important role (see Eccles \& Wigfield, 2002; Trautwein \& Lüdtke, 2007). Further, a study by Goetz, Cronjaeger, et al. (2010), Goetz, Nett, et al., (submitted for publication) showed that relations between achievement emotions and academic self concept are significantly stronger in mathematics than in lan guages. At the same time, to fully understand the complexity of achievement emotions, and to derive practical implications for teachers and interventions, research clearly needs to explore achievement emotions within an interindividual and an intraindi vidual framework spanning various school subjects (Pekrun, 2006). Future studies should thus examine the domain specificity of homework related emotions, their antecedents and consequences.

\section{Outlook}

Homework is an issue of tremendous everyday importance for students, parents, and teachers. The present study significantly ex tends previous homework research by focusing on emotional expe riences during homework sessions. With its large sample size and longitudinal dataset, our study casts light on the interrelations between the learning environment, the development of home work related emotions, students' homework effort, and mathe matics achievement. As homework is such a time intensive and contentious aspect of school learning, more research is clearly war ranted into how homework assignments affect students' emotions and into how emotional experiences in homework settings influ ence learning.

\section{References}

Adams, R., \& Wu, M. (2002). PISA 2000: Technical report. Paris, France: OECD.

Baumert, J., Kunter, M., Blum, W., Brunner, M., Voss, T., Jordan, et al. (2010). Teachers' mathematical knowledge, cognitive activation in the classroom, and student progress. American Educational Research Journal, 47, 133-180. doi:0.3102/0002831209345157.

Cacioppo, J. T., Berntson, G. G., Larsen, J. T., Poehlmann, K. M., \& Ito, T. A. (2000). The psychophysiology of emotion. In M. Lewis \& J. M. Haviland-Jones (Eds.) Handbook of emotions (2nd ed., pp. 173-191). New York, NY: Guilford.

Chen, C., \& Stevenson, H. (1989). Homework: A cross-cultural examination. Child Development, 60, 551-561. doi:10.2307/1130721.

Cooper, H. (1989). Homework. White Plains, NY: Longman.

Corno, L., \& Xu, J. (2004). Homework as the job of childhood. Theory into Practice, 43, 227-233. doi:10.1207/s15430421tip4303_9.

Dettmers, S., Trautwein, U., Lüdtke, M., Kunter, M., \& Baumert, J. (2010). Homework works if homework quality is high: Using multilevel modeling to predict the development of achievement in mathematics. Journal of Educational Psychology, 102, 467-482. doi:10.1037/a0018453

Eccles, J. S., \& Wigfield, A. (2002). Motivational beliefs, values, and goals. Annual Review of Psychology, 53, 109-132. doi:10.1146/annurev.psych.53.100901. 135153.

Else-Quest, N. M., Hyde, J. S., \& Hejmadi, A. (2008). Mother and child emotions during mathematics homework. Mathematical Thinking and Learning, 10, 5-35. doi:10.1080/10986060701818644.

Enders, C. K., \& Tofighi, D. (2007). Centering predictor variables in cross-sectional multilevel models: A new look at an old issue. Psychological Methods, 12, 121-138. doi:10.1037/1082-989X.12.2.121.

Frenzel, A., Pekrun, R., \& Goetz, T. (2007). Perceived learning environment and students' emotional experiences: A multilevel analysis of mathematics 
classrooms. Learning and Instruction, 17, 478-493. doi:10.1016/ j.learninstruc.2007.09.001.

Ganzeboom, H. B. G., de Graaf, P. M., Treiman, D. J., \& de Leeuw, J. (1992). A standard international socio-economic index of occupational status. Social Science Research, 21, 1-56. doi:10.1007/BF03173468.

Goetz, T., Cronjaeger, H., Frenzel, A. C., Lüdtke, O., \& Hall, N. C. (2010). Academic selfconcept and emotion relations: Domain specificity and age effects Contemporary Educational Psychology, 35, 44-58. doi:10.1016/j.cedpsych.2009. 10.001.

Goetz, T., Frenzel, A., Hall, N., \& Pekrun, R. (2008). Antecedents of academic emotions: Testing the internal/external frame of reference model for academic enjoyment. Contemporary Educational Psychology, 33, 9-33. doi:10.1016/ j.cedpsych.2006.12.002.

Goetz, T., Frenzel, A. C., \& Pekrun, R. (2006). The domain specificity of academic emotional experiences. The Journal of Experimental Education, 75, 5-29. doi:10.3200/JEXE.75.1.5-29.

Goetz, T., Frenzel, C. A., Pekrun, R., Hall, N. C., \& Lüdtke, O. (2007). Between- and within-domain relations of students' academic emotions. Journal of Educational Psychology, 99, 715-733. doi:10.1037/0022-0663.99.4.715.

Goetz, T., Nett, U., Martiny, S., Hall, N. C., Pekrun, R., Dettmers, S., \& Trautwein, U. (submitted for publication). Students' emotions experienced when doing homework: Structures, self-concept antecedents, and achievement outcomes.

Heller, K. A., \& Perleth, C. (2000). Kognitiver Fähigkeitstest für 4.-12. Klassen, revision $($ KFT $4-12+R)$ (Cognitive abilities test, revised version (KFT $4-12+R)$ ). Göttingen, Germany: Hogrefe.

Karabenick, S. A. (2004). Perceived achievement goal structure and college student help seeking. Journal of Educational Psychology, 96, 569-581. doi:10.1037/0022 0663.96.3.569

Krull, J. L., \& MacKinnon, D. P. (2001). Multilevel modeling of individual and grouplevel mediated effects. Multivariate Behavioral Research, 36, 249-277. doi:10.1207/S15327906MBR3602_06.

Kunter, M., \& Baumert, J. (2006). Who is the expert? Construct and criteria validity of student and teacher ratings of instruction. Learning Environment Research, 9, 231-251. doi:10.1007/s10984-006-9015-7.

Leone, C. M., \& Richards, M. H. (1989). Classwork and homework in early adolescence. The ecology of achievement. Journal of Youth and Adolescence, 18 531-548. doi:10.1007/BF02139072.

Linnenbrink, E. A. (2007). The role of affect in student learning: A multi-dimensional approach to considering the interaction of affect, motivation, and engagement. In P. A. Schutz \& R. Pekrun (Eds.), Emotion in education (pp. 107-124). Oxford, UK: Elsevier. doi:10.1016/B978-012372545-5/50008-3.

Lüdtke, O., Marsh, H. W., Robitzsch, A., Trautwein, U., Asparouhov, T., \& Muthén, B. (2008). The multilevel latent covariate model: A new, more reliable approach to group-level effects in contextual studies. Psychological Methods, 13, 203-229. doi:10.1037/a0012869.

Lüdtke, O., Robitzsch, A., Trautwein, U., \& Kunter, M. (2009). Assessing the impact of learning environments: How to use student ratings of classroom characteristics in multilevel modeling. Contemporary Educational Psychology, 34, 120-131. doi:10.1016/j.cedpsych.2008.12.001.

Meyer, D., \& Turner, J. (2006). Re-conceptualizing emotion and motivation to learn in classroom contexts. Educational Psychology Review, 18, 377-390. doi:10.1007| s10648-006-9032-1.

Muthén, L. K., \& Muthén, B. O. (1998-2007). MPlus user's guide. Los Angeles, CA: Muthén \& Muthén.

Op't Eynde, P., \& Turner, J. (2006). Focusing on the complexity of emotion issues in academic learning: A dynamical component systems approach. Educationa Psychology Review, 18, 361-376. doi:10.1007/s10648-006-9031-2.

Pekrun, R. (2006). The control-value theory of achievement emotions: Assumptions, corollaries, and implications for educational research and practice. Educational Psychology Review, 18, 315-341. doi:10.1007/s10648006-9029-9.

Pekrun, R., Frenzel, A. C., Goetz, T., \& Perry, R. P. (2007). Theoretical perspectives on emotions in education. In P. A. Schutz \& R. Pekrun (Eds.), Emotion in education (pp. 13-36). Oxford, UK: Elsevier. doi:10.1016/B978-012372545-5/50003-4.

Pekrun, R., Goetz, T., Daniels, L. M., Stupnisky, R. H., \& Perry, R. P. (2010). Boredom in achievement settings: Control-value antecedents and performance consequences of a neglected emotion. Journal of Educational Psychology, 102, 531-549. doi:10.1037a0019243.
Pekrun, R., Goetz, T., Titz, W., \& Perry, R. P. (2002). Academic emotions in students' self-regulated learning and achievement: A program of qualitative and quantitative research. Educational Psychologist, 37, 91-105. doi:10.1207/ S15326985EP3702_4.

Peugh, J. L., \& Enders, C. K. (2004). Missing data in educational research: A review of reporting practices and suggestions for improvement. Review of Educational Research, 74, 525-556. doi:10.3102/00346543074004525.

Prenzel, M., Carstensen, C., Schöps, K., \& Maurischat, C. (2006). Die Anlage des Längsschnitts bei PISA 2003 (The longitudinal design of the PISA 2003 study). In M. Prenzel, J. Baumert, W. Blum, R. Lehmann, D. Leutner, M. Neubrand, R. Pekrun, J. Rost, \& U. Schiefele (Eds.), PISA 2003. Untersuchungen zur Kompetenzentwicklung im Verlauf eines Schuljahres (pp. 29-62). Münster, Germany: Waxmann.

Raudenbush, S. W., \& Bryk, A. S. (2002). Hierarchical linear models (2nd ed.). Thousand Oaks, CA: Sage.

Rubin, D. B. (1987). Multiple imputation for nonresponse in surveys. New York, NY: Wiley.

Schafer, J. L. (2001). Multiple imputation with pan. In L. M. Collins \& A. G. Sayer (Eds.), New methods for the analysis of change (pp. 357-377). Washington, DC: American Psychological Association. doi:10.1037/10409-012.

Schafer, J. L. (2008). The pan package. <http://cran.r-project.org/web/packages/pan/ pan.pdf>. Retrieved 04.04.08.

Thorndike, R. L., \& Hagen, E. (1993). The cognitive abilities test: Form 5. Itasca, IL: The Riverside Publishing Company.

Trautwein, U. (2007). The homework-achievement relation reconsidered: Differentiating homework time, homework frequency, and homework effort. Learning and Instruction, 17, 372-388. doi:10.1016/j.learninstruc.2007.02.009.

Trautwein, U., \& Lüdtke, O. (2007). Students' self-reported effort and time on homework in six school subjects: Between-students differences and withinstudent variation. Journal of Educational Psychology, 99, 432-444. doi:10.1037| 0022-0663.99.2.432

Trautwein, U., \& Lüdtke, O. (2009). Predicting homework motivation and homework effort in six school subjects: The role of person and family characteristics, classroom factors, and school track. Learning and Instruction, 19, 243-258.

Trautwein, U., Lüdtke, O., Kastens, C., \& Köller, O. (2006). Effort on homework in grades 5 through 9: Development, motivational antecedents, and the association with effort on classwork. Child Development, 77, 1094-1111. doi:10.1111/j.1467-8624.2006.00921.x.

Trautwein, U., Lüdtke, O., Roberts, B. W., Schnyder, I., \& Niggli, A. (2009). Different forces, same consequence. Conscientiousness and competence beliefs are independent predictors of academic effort and achievement. Journal of Personality and Social Psychology, 97, 1115-1128. doi:10.1037/a0017048.

Trautwein, U., Lüdtke, O., Schnyder, I., \& Niggli, A. (2006). Predicting homework effort: Support for a domain-specific, multilevel homework model. Journal of Educational Psychology, 98, 438-456. doi:10.1037/0022-0663.98.2.438.

Trautwein, U., Niggli, A., Schnyder, I., \& Lüdtke, O. (2009). Between-teacher differences in homework assignments and the development of students' homework effort, homework emotions, and achievement. Journal of Educational Psychology, 101, 176-189. doi:10.1037/0022-0663.101.1.176.

Trautwein, U., Schnyder, I., Niggli, A., Neumann, M., \& Lüdtke, O. (2009). Chameleon effects in homework research: The homework-achievement association depends on the measures used and the level of analysis chosen. Contemporary Educational Psychology, 34, 77-88. doi:10.1016/j.cedpsych.2008.09.001.

Turner, J. E., \& Schallert, D. L. (2001). Expectancy-value relationships of shame reactions and shame resiliency. Journal of Educational Psychology, 93, 320-329. doi:10.1037/0022-0663.93.2.320.

Verma, S., Sharma, D., \& Larson, R. W. (2002). School stress in India: Effects on time and daily emotions. International Journal of Behavioral Development, 26, 500-508. doi:10.1080/01650250143000454.

Warton, P. (2001). The forgotten voices in homework: Views of students. Educational Psychologist, 36, 155-165. doi:10.1207/S15326985EP3603_2.

Weiner, B. (1985). An attributional theory of achievement motivation and emotion. Psychological Review, 92, 548-573. doi:10.1037/0033-295X.92.4.548.

Wigfield, A., \& Wagner, A. L. (2005). Competence, motivation, and identity development during adolescence. In A. J. Elliot \& C. S. Dweck (Eds.), Handbook of competence and motivation (pp. 222-239). New York, NY: Guilford.

$\mathrm{Xu}, \mathrm{J}$. (2005). Homework emotion management reported by high school students. The School Community Journal, 15, 21-36. 